\title{
Investigating the bone metabolic parameters and serum 25- hydroxyvitamin D levels in male patients with asymptomatic hyperuricemia
}

Orsolya Dóra Ács ${ }^{1}$, Emőke Csupor ${ }^{2}$, Viktória Ferencz ${ }^{3}$,Szilvia Mészáros ${ }^{3}$, Edit Tóth ${ }^{4}$, Gábor Farkas ${ }^{5}$, Csaba Horváth ${ }^{3}$

${ }^{1}$ Semmelweis University School of Ph.D. Studies, Budapest, Hungary ${ }^{2}$ The Health Service of Budavári Local Authorities, Budapest, Hungary ${ }^{3} 1$ st Department of Medicine, Semmelweis University, Budapest, Hungary ${ }^{4}$ Department of Rheumatology, County Hospital Flór Ferenc, Kistarcsa, Hungary ${ }^{5}$ Centrum-Lab. KFT, Budapest, Hungary

\section{INTRODUCTION}

\section{MATERIALS AND METHODS}

Over the past few years the clinical relevance of serum uric acid level has changed. The elevated serum uric acid level not only impairs the joints and the kidney function but it is also linked with an increased risk of cardivascular diseases.

The aim of our study was to examine how bones are affected (change of bone mineral density, bone metabolism parameters, serum 25-hydroxyvitamin $D$ levels and frequency of fractures) by elevated serum uric acid level.
We investigated a total of 136 patients divided into two groups according to serum uric acid level: 68 male patients with (age: $54.9 \pm 1.6$ years) and 68 male patients without (age: $55.2 \pm 1,9$ years) hyperuricemia. In all cases hyperuricemia ( se level $>416$ umol/l ) was asymptomatic.

Bone mineral density (BMD) was measured by dual-energy X-ray absorptiometry (DEXA), for bone markers such as: parathyroid hormone $(\mathrm{PTH}), \quad \beta$-CrossLaps, 25-(OH) vitamin D3 and osteocalcin (OC) electrochemiluminescence immunoassay were used and routine labor parameters were measured. Medical history including prevalence of bone fractures was also recorded. Statistical analysis was performed by ANOVA, with post-hoc Bonferroni correction. (Satistica software 9.0)

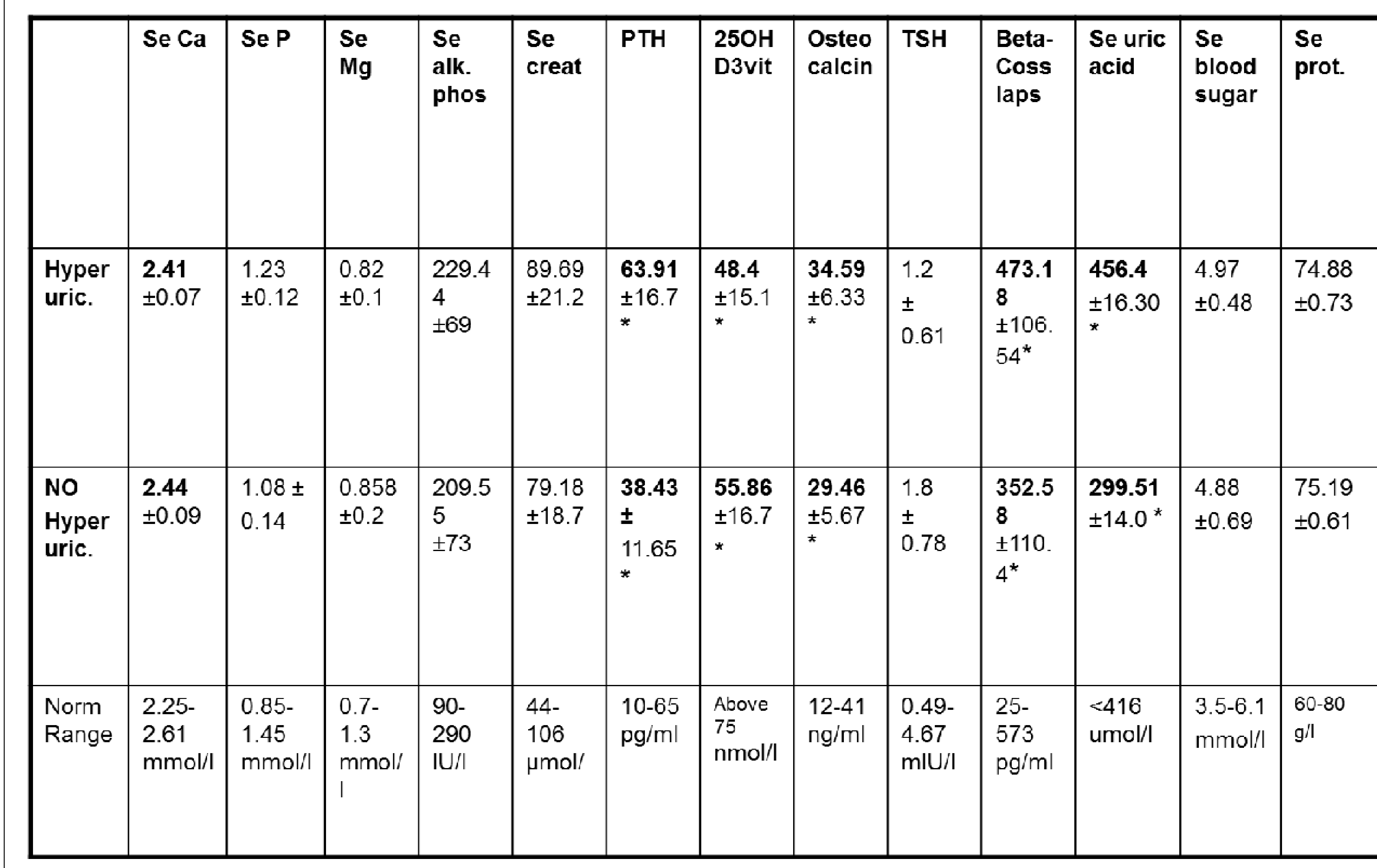

$*<0.05$

\begin{tabular}{|l|l|l|l|l|}
\hline Patients & $\begin{array}{l}\text { Age } \\
(\mathbf{y r s}) \pm \text { SD }\end{array}$ & $\begin{array}{l}\text { Weight } \\
(\mathbf{k g}) \pm \text { SD }\end{array}$ & $\begin{array}{l}\text { Height } \\
(\mathbf{m}) \pm \text { SD }\end{array}$ & $\begin{array}{l}\text { BMI } \\
\left(\mathbf{k g} / \mathbf{m}^{2}\right) \pm S D \\
(\mathrm{n:}: 18.5-24.9 \mathrm{~K} / \mathrm{m} 2)\end{array}$ \\
\hline $\begin{array}{l}\text { Hyperuric. } \\
\mathbf{n}=68\end{array}$ & $54.9 \pm 1.6$ & $84.18 \pm 7.51$ & $\begin{array}{l}1.76 \pm 0.074 \\
*\end{array}$ & $\begin{array}{l}27.05 \pm 2.20 \\
*\end{array}$ \\
\hline $\begin{array}{l}\text { NO } \\
\text { Hyperuric. } \\
\mathrm{n}=\mathbf{6 8}\end{array}$ & $55.2 \pm 1.9$ & $85.92 \pm 6.4$ & $\begin{array}{l}1.82 \pm 0.056 \\
*\end{array}$ & $\begin{array}{l}25.83 \pm 2.56 \\
*\end{array}$ \\
\hline
\end{tabular}

\begin{tabular}{|l|l|l|l|l|l|}
\hline & $\begin{array}{l}\text { L2-4 } \\
\text { Zsc } \pm \text { SD }\end{array}$ & $\begin{array}{l}\text { L2-4 } \\
\text { Tsc } \pm \text { SD }\end{array}$ & $\begin{array}{l}\text { Lumbar } \\
\text { Zsc } \pm \text { SD }\end{array}$ & $\begin{array}{l}\text { Femoral } \\
\text { Tsc } \pm \text { SD }\end{array}$ & Fractures \\
\hline $\begin{array}{l}\text { Hyperuric. } \\
n=68\end{array}$ & $-1.11 \pm 0.15^{*}$ & $-2.53 \pm 0.20 *$ & $-1.07 \pm 0.11^{*}$ & $-2.45 \pm 0.16^{*}$ & $17 \sim 25 \%$ \\
\hline $\begin{array}{l}\text { No } \\
n=68\end{array}$ & $-0.48 \pm 0.15^{*}$ & $-1.91 \pm 0.20^{*}$ & $-0.61 \pm 0.1 *$ & $-1.98 \pm 0.15^{*}$ & $7 \sim 10 \%$ \\
\hline
\end{tabular}

\section{RESULTS}

In patients with asymptomatic hyperuricemia lumbar spine (L2-4) BMD (T-score: $-2.53 \pm 0.20$ vs $-1.91 \pm 0.20, p<0.05$ ) and left femoral neck BMD (T-sc: $-2.45 \pm 0.16$ vs $-1.98 \pm 0.15, p<0.05$ ) were lower than in patients without hyperuricemia. Serum 25-(OH) vitamin D3 levels were also lower in the hyperuricemic group (48.4 $\mathrm{nmol} / \mathrm{l} \pm 15.1 \mathrm{vs}$ $55.86 \mathrm{nmol} / \mathrm{l} \pm 16.7, \mathrm{p}<0.05)$. Bone fracture had occurred in 17 of 68 hyperuricemic patients, while in the nonhyperuricemic group only 7 fractures were recorded.

\section{CONCLUSIONS}

The in-time recognition and treatment of elevated serum uric acid level could positively influnce the bone metabolism and be part of fracture prevention.

\section{REFERENCES}

Arthritis Res Ther. 2013; 14(2): Mar 10. 2012. doi: 10.1186/ar3769
The independent association between parathyroid hormone levels and hyperuricemia: a
national population stsdy
Janet Y Hui. Jee Woong J Choi.David B Mount. Yanyan Zhu. Yuqing Zhang. Hyon K Choi
1Janet Y Hui.Jee Woong J Choi. David B Mount. Yanyan Zhu. Yuqing Zhang. and Hyon K
Choi
Bone Miner Res. 2014 May:26(5):955-64. doi: 10.1002/jbmr.286.
Serum uric acid is associated with bone health in older men: a cross-sectional population-
based study.
Nabipour I. Sambrook PN. Blyth FM. Janu MR. Waite LM. Naganathan V. Handelsman
DJ. Le Couteur DG. Cumming RG. Seibel MJ.

